\title{
Reliability of the Ultrasound Cardiac Output Monitor for Pediatric Patients
}

\author{
Joris Lemson ${ }^{1} \cdot$ Shane M. Tibby ${ }^{2}$
}

Received: 12 December 2015/ Accepted: 4 February 2016/Published online: 18 March 2016

(C) Springer Science+Business Media New York 2016

Sir, with interest we read the recent study by Beltramo and colleagues regarding a validation study of the UScom device for measuring cardiac output in children [1]. We would like to compliment the authors with their work since validating these devices in children is important but difficult to perform. However, we have three remarks.

First, the study population consisted of mainly older children with a cardiac output (except for two children) higher than $31 / \mathrm{min}$. This does not reflect a general PICU population in which the mean age is often around 4 years.

Second, besides the accuracy in measuring absolute values of cardiac output, trending of these parameters is often of more importance. This needs additional validation.

Third and most importantly, the authors compare their results with others by using the percentage error (PE). They report a PE of $11 \%$. This is an extremely low value that is never reported in clinical studies [3]. We are afraid the authors made an error in calculating this important value. According to Critchley et al. [2], the PE is calculated by $(2 \times \mathrm{SD}$ of the bias $) /$ mean value. The authors seam to have made a wrong calculation since if we take the values from the text and the Bland-Altman plot (fig. 1), the limit of agreement is $1.4 \mathrm{l} / \mathrm{min}$ and the mean value is around
$4.3 \mathrm{l} / \mathrm{min}$. This produces a PE around $33 \%$ which is higher than the accepted threshold of $30 \%$.

Therefore, we believe that this technology cannot be recommended as a reliable measurement of cardiac output in (young) children until further validation has been performed.

\section{Compliance with ethical standards}

Conflict of interest The authors declare that they have no conflict of interest.

\section{References}

1. Beltramo F, Menteer J, Razavi A, Khemani RG, Szmuszkovicz J, Newth CJ, Ross PA (2015) Validation of an ultrasound cardiac output monitor as a bedside tool for pediatric patients. Pediatr Cardiol 37(1):177-183

2. Critchley LA, Critchley JA (1999) A meta-analysis of studies using bias and precision statistics to compare cardiac output measurement techniques. J Clin Monit Comput 15(2):85-91

3. Nusmeier A, van der Hoeven JG, Lemson J (2010) Cardiac output monitoring in pediatric patients. Expert Rev Med Devices 7(4):503-517

Joris Lemson

joris.lemson@radboudumc.nl

1 Radboud University Medical Center, Nijmegen, Netherlands

2 Paediatric Intensive Care Unit, Evelina Children's Hospital, Guy's and St Thomas' NHS Foundation Trust, London, UK 